\title{
A Laboratory Study on the Performance of Geosynthetic Reinforced Asphalt Overlays
}

\author{
Jaime Obando-Ante • Ennio M. Palmeira
}

Received: 2 December 2014/ Accepted: 16 December 2014/Published online: 15 January 2015

(C) Springer International Publishing AG 2015

\begin{abstract}
Geosynthetics can improve pavement performance in different ways, such as drainage layers, reinforcement and barriers. The use of geosynthetic reinforcement in pavement base and cap layers has increased markedly in the last decades mainly because of better overall performance and greater life of reinforced pavements in comparison with unreinforced ones, as reported in several laboratory and field experiments. This paper presents and discusses results of laboratory load tests on reinforced and unreinforced asphalt concrete layers focusing on the use of geogrids as reinforcement in asphalt overlays. Cyclic loads were applied by a loading platen on asphalt concrete beams consisting of a new cap overlying a cracked cap resting on a compressible layer. Four different types of reinforcements were tested between the new and the damaged asphalt concrete caps under varying values of cyclic loads. The reinforcements tested consisted of a geocomposite, 2 polymeric grids and a wire mesh. The results obtained showed the marked increase in the number of load repetitions due to the use of geogrid reinforcement and that adherence between asphalt concrete and reinforcement is a key issue for a good performance of reinforced overlays.
\end{abstract}

Keywords Geosynthetics - Reinforcement - Pavements · Asphalt overlays

\section{List of symbols \\ $C_{\mathrm{U}} \quad$ Coefficient of uniformity $\left(=D_{60} / D_{10}\right)$ (dimensionless)}

J. Obando-Ante · E. M. Palmeira ( $\square)$

Department of Civil and Environmental Engineering, University

of Brasília, FT, Brasília, DF 70910-900, Brazil

e-mail: palmeira@unb.br

J. Obando-Ante

e-mail: jaime_obando87@hotmail.com
$C_{\mathrm{C}} \quad$ Coefficient of curvature $\left(D_{30}^{2} / D_{10} D_{60}\right)$ (dimensionless)

$D_{n} \quad$ Diameter for which $n \%$ of the remaining particles are smaller than that diameter $(\mathrm{m})$

ER Efficiency ratio (dimensionless)

$G_{\mathrm{mb}} \quad$ Asphalt concrete specific gravity (dimensionless)

$G_{\mathrm{mm}} \quad$ Asphalt concrete maximum theoretical specific gravity (dimensionless)

$J_{5 \%} \quad$ Secant reinforcement tensile stiffness at $5 \%$ strain

$N \quad$ Number of load repetitions (dimensionless)

$P_{\mathrm{b}} \quad$ Total binder content (dimensionless)

$T_{\max } \quad$ Reinforcement tensile strength (N/m)

$\varepsilon_{\max }$ Maximum reinforcement tensile strain (dimensionless)

$\sigma \quad$ Vertical stress applied on the beam top (Pa)

\section{Introduction}

The use of geosynthetic to improve the performance of pavements has increased markedly in the last years [1-18]. Different types of geosynthetics can be used to improve pavement performance with varying functions (reinforcement, drainage and barriers). Geogrids and geotextiles can be employed to reinforce the pavement base or asphalt cap. Geotextiles impregnated with asphalt can be used to avoid pumping of fines from the base or subgrade through cracks in the asphalt cap. In addition to traditional filter applications, nonwoven geotextiles can be used as capillary barriers to reduce pavement base moistening or saturation. When impregnated with asphalt they can also function as barrier against moistening of pavement layers. Ribeiro et al. [19] described a successful field application of an asphalt impregnated nonwoven geotextile layer enveloping 
a fine grained soil used as pavement base layer to avoid moisture content increase in the latter. Geosynthetics (geogrids, geotextiles and geocomposites) can also be successfully applied in pavement asphalt overlays.

Austin and Gilchrist [5] investigated the use of a geocomposite to minimise crack reflection in real scale experiments. One of the reinforced sections had the geocomposite installed at the middle of the asphalt layer and the other at its base. The test sections were subjected to a tire pressure of $300 \mathrm{kPa}$. The results showed that the reinforced layers resisted three times more load repetitions than the control unreinforced section. Similar studies and conclusions were obtained by Fritzen [20].

Hosseini et al. [14] described the use of geogrid reinforcement in pavements in the Khomeini Airport, Tehran, Iran. Tests were carried out on prismatic specimens extracted from the pavement, according to ASTM D 7460 [21], with a load frequency of $10 \mathrm{~Hz}$. The results showed that the reinforced specimens presented greater stiffness and lower crack reflection than the unreinforced ones.

The evaluation of the performance of high tensile stiffness geogrids in pavements was carried out by Komatsu et al. [22]. Test using reinforced and unreinforced layers in a traffic simulator showed that the presence of the reinforcement reduced the formation of ruts and that the adherence between geogrid and asphalt layer was a very important factor for geogrid performance.

Field experiments have also shown that the use of geogrid reinforcement can improve asphalt overlay performance. Fritzen [20] investigated the performance of different reinforcement types in experimental sections in a highway in Brazil that were subjected to accelerated traffic simulation. The best performance was observed in the experimental site where geogrid reinforcement was employed. Similar results were obtained by Zou et al. [23] in field experiments in a reinforced cap on a cement stabilized base. In the experiments fibre glass and polymeric geogrids were used as well as two geotextiles and a geocomposite. The results obtained showed less surface rutting in the reinforced sections in comparison with the reference unreinforced section.

Montestruque [24] conducted laboratory tests on reinforced and unreinforced asphalt concrete beams aiming at investigating the use of geosynthetic reinforcement in pavement overlays. Geogrids and a nonwoven geotextile were used as reinforcements. The results showed a better performance of the geogrid reinforced specimens in comparison with the geotextile reinforced and with the unreinforced specimens. Similar tests were carried out by Bühler [25], where the use of geogrid reinforcement improved the performance of the overlay layer with regard to crack reflection. Khodaii et al. [15] and Barraza et al. [18] carried out similar tests also finding that the use of geogrid reinforcement improved the performance of the overlay with respect to the reduction of crack reflection. Barraza et al. [18] observed a better performance of overlays reinforced with stiffer geogrids. The Four Point Beam Bending Test has also been employed in the study on

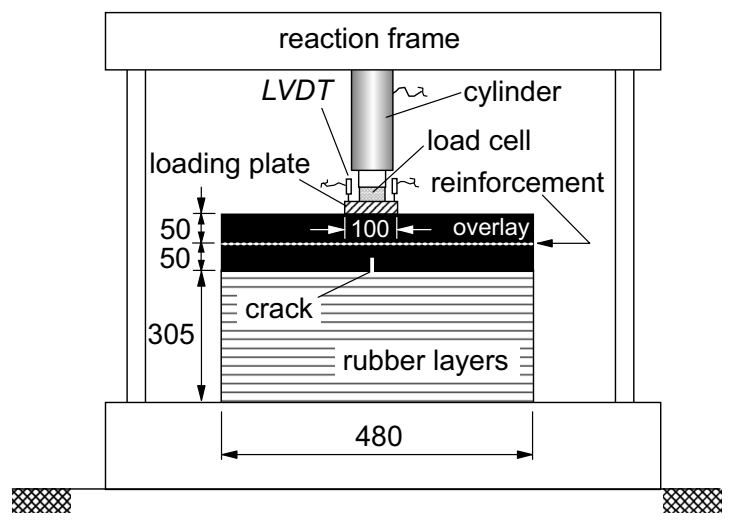

Dimensions in $\mathrm{mm}$

(a)

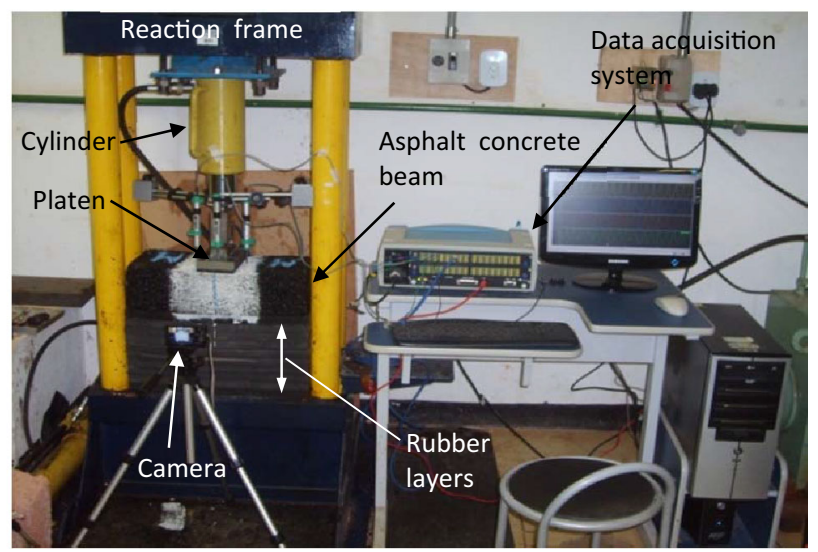

(b)

Fig. 1 Equipment used in the tests. a Geometrical characteristics of the equipment. b View of the equipment during a test

Table 1 Characteristics of the asphalt concrete

\begin{tabular}{ll}
\hline Property & \\
\hline Percentage of aggregate \% & 95.0 \\
Total binder content \% $\left(P_{\mathrm{b}}\right)$ & 5.0 \\
Air voids \% & 4.93 \\
Voids in the mineral aggregate \% & 14.59 \\
Bulk specific gravity $\left(G_{\mathrm{mb}}\right)$ & 2.404 \\
Maximum theoretical specific gravity $\left(G_{\mathrm{mm}}\right)$ & 2.529 \\
Marshall stability $(\mathrm{N})$ & 9,751 \\
Marshall flow $(\mathrm{mm})$ & 4.5 \\
Stability Marshall/flow ratio $(\mathrm{N} / \mathrm{mm})$ & 2166 \\
Dust/asphalt ratio & 2.23 \\
\hline
\end{tabular}


Table 2 Aggregate properties

\begin{tabular}{lc}
\hline Property & \\
\hline Shape index & 0.6 \\
Sand angularity (\%) & 42.5 \\
Sand equivalent (\%) & 64.0 \\
$D_{85}(\mathrm{~mm})$ & 8.8 \\
$D_{50}(\mathrm{~mm})$ & 3.4 \\
$D_{10}(\mathrm{~mm})$ & 0.11 \\
$C_{\mathrm{U}}$ & 41.9 \\
$C_{\mathrm{C}}$ & 4.3 \\
Los angeles abrasion $(\%)$ & 15.6 \\
\hline
\end{tabular}

$D_{n}=$ diameter for which $n \%$ of the remaining particles are smaller than that diameter; $C_{\mathrm{U}}=$ coefficient of uniformity $\left(=D_{60} / D_{10}\right)$, $C_{\mathrm{C}}=$ coefficient of curvature $\left(D_{30}^{2} / D_{10} D_{60}\right)$

the use of reinforcement in asphalt overlays. Virgili et al. [16], Ferrotti et al. [17] and Pasquini et al. [26] report good performance of geogrid reinforced overlays in this type of test.

The interaction mechanism between a geosynthetic reinforcements and an asphalt layer is quite complex and the level of benefit brought by the use of such reinforcement depends on several factors (properties of materials, loading conditions, temperature, etc.). Because of such complexity, further research is needed on this type of geosynthetic application. In this context, this paper presents results of laboratory experiments on unreinforced and reinforced asphalt concrete beams subjected to cyclic loading. The performance of different types of geogrids and of a geocomposite was investigated. The results obtained are presented and discussed in the following sections.

\section{Experimentals}

\section{Equipment}

The equipment used in the tests is schematically shown in Fig. 1a. A view of the equipment during one of the tests is presented in Fig. 1b. It consisted of a hydraulic cylinder that applied the vertical load on a plate with dimensions $100 \mathrm{~mm}$ (width) $\times 200 \mathrm{~mm}$ (length) $\times 25 \mathrm{~mm}$ (thickness), resting on the top of the asphalt concrete beam specimen. The vertical load on the loading plate was varied to produce vertical stresses on the beam equal to 350,450 and $560 \mathrm{kPa}$ (typical tire pressure value in Brazil) and was applied at a frequency of $1 \mathrm{~Hz}$. The asphalt concrete beam rested on a pile of stiff (Young's modulus of $21 \mathrm{MPa}$ ) rubber layers, $305 \mathrm{~mm}$ high, to simulate a hypothetical pavement base. A load cell and displacement transducers allowed for the measurement of loads and displacements during the tests. A data acquisition system acquired the signals from the instrumentation automatically. The tests were ended when a vertical displacement of the loading plate of $25 \mathrm{~mm}$ was reached.

It should be pointed out that the type of test employed is an approximation of a real situation, where tyres of a moving vehicle load the pavement. In this case additional stresses may be mobilised in the pavement layers due to inertia forces, for instance. In spite of these limitations, the type of apparatus and testing methodology employed were the same for reinforced and unreinforced situations, which allowed comparisons between these situations under the same loading and geometrical conditions.

The tests were filmed with a digital camera to allow the identification of crack formation or reflection during the

Table 3 Properties of the reinforcements

\begin{tabular}{|c|c|c|c|c|}
\hline & $G 1$ & $G 2$ & G3 & G4 \\
\hline \multicolumn{5}{|l|}{ MD } \\
\hline$T_{\max }(\mathrm{kN} / \mathrm{m})$ & 38 & 49 & 128 & 55 \\
\hline$J_{5 \%}(\mathrm{kN} / \mathrm{m})$ & 585 & 2320 & 1,390 & 875 \\
\hline$\varepsilon_{\max }(\%)$ & $9.1 \%$ & $4.5 \%$ & $14.2 \%$ & $7.6 \%$ \\
\hline \multicolumn{5}{|l|}{ CMD } \\
\hline$T_{\max }(\mathrm{kN} / \mathrm{m})$ & 34 & 49 & 48 & 43 \\
\hline$J_{5 \%}(\mathrm{kN} / \mathrm{m})$ & 657 & 2,055 & 557 & 585 \\
\hline$\varepsilon_{\max }(\%)$ & $12.1 \%$ & $4.7 \%$ & $11.1 \%$ & $9.3 \%$ \\
\hline Type & Geocomposite & Wire mesh & Geogrid & Geogrid \\
\hline Material & PET & Steel & PET & PET \\
\hline Aperture dimensions (mm) & $40 \times 40$ & $20 \times 20$ & $20 \times 20$ & $20 \times 20$ \\
\hline Mass per unit area $\left(\mathrm{g} / \mathrm{m}^{2}\right)$ & 270 & 1,850 & 440 & 280 \\
\hline
\end{tabular}

$M D$ machine direction, $C M D$ cross-machine direction, $P E T$ polyester, $T_{\max }$ tensile strength (wide strip tensile tests according to ASTM D6637 [27]), $J_{5 \%}=$ secant tensile stiffness at $5 \%$ strain from wide strip tensile tests; $\varepsilon_{\max }=$ maximum tensile strain from wide strip tensile tests 


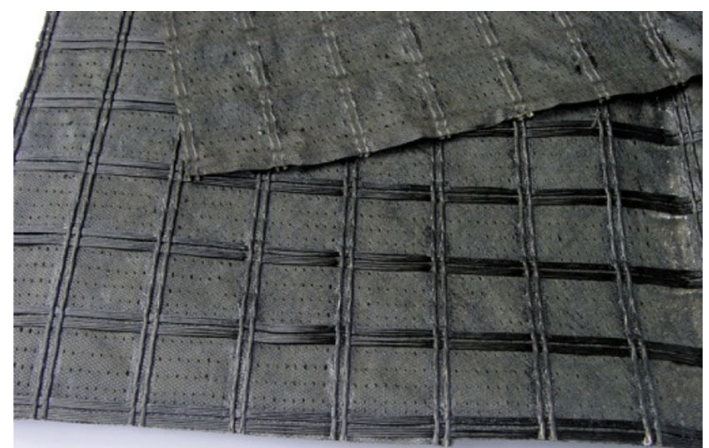

(a)

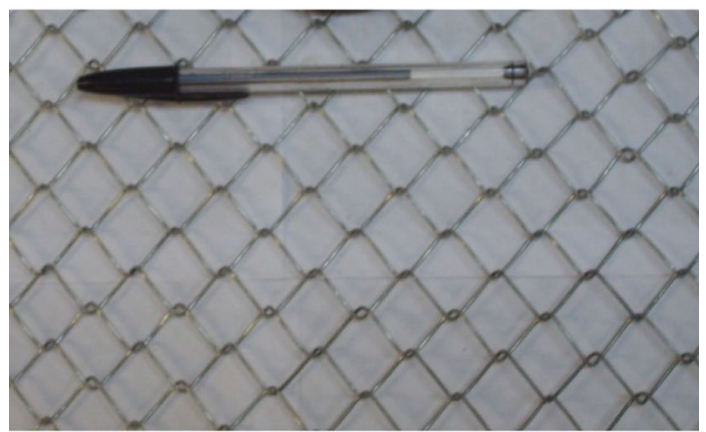

(b)

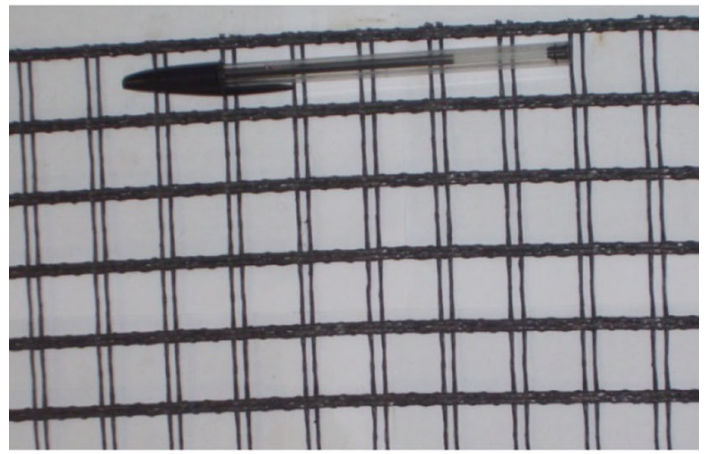

(c)

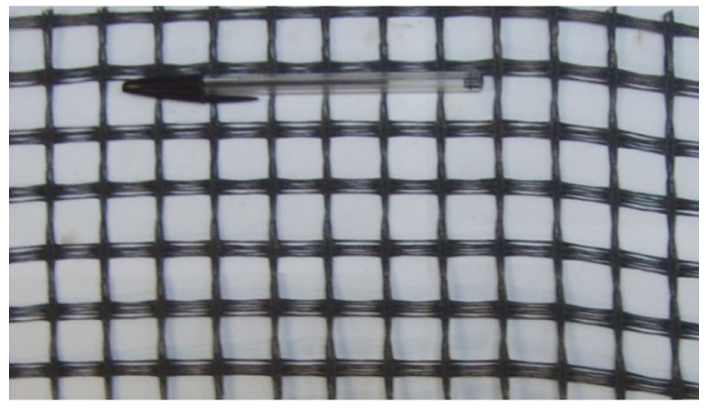

(d)

Fig. 2 Reinforcements used in the tests. a Reinforcement G1. b Reinforcement $G 2$. c Reinforcement $G 3$. d Reinforcement $G 4$

tests. The side of the beam underneath the loading plate was painted white to better expose crack development (Fig. 1b).

\section{Asphalt Concrete Beams}

The asphalt concrete beams were moulded by static compression in a rigid container. The beams were $480 \mathrm{~mm}$ long, $200 \mathrm{~mm}$ wide and $100 \mathrm{~mm}$ thick (Fig. 1a). The top beam simulated a new overlay $50 \mathrm{~mm}$ thick over a damaged cap, also $50 \mathrm{~mm}$ thick, with or without reinforcement between them, depending on the test configuration (Fig. 1a). CAP 50-70 asphalt binder was used in the preparation of the beams. The relevant properties of the asphalt concrete are presented in Table 1. A tack-coat (cationic, with viscosity degree equal to $1-\mathrm{RR}-1 \mathrm{C}$ ) was used during beam preparation to favour the adherence between the reinforcement and the asphalt concrete. The aggregate used to prepare the beams had particle diameters smaller than $25 \mathrm{~mm}$. The relevant properties of the aggregate are listed in Table 2.

The optimum content of the asphalt binder in the mixture used to manufacture the beams was determined using Marshall's method of asphalt concrete mix design. The tests carried out on the asphalt binder and asphalt concrete followed the standards of the Brazilian National Department of Transportation Infrastructure (DNIT).

For the asphalt concrete beam preparation the aggregate and the asphalt cement were heated at temperatures of $160^{\circ}$ and $150^{\circ}$, respectively, prior to mixing. The mixture was then submitted to a static vertical stress equal to $312.5 \mathrm{kPa}$. The beam formed under such conditions showed the properties listed in Table 1. In reinforced tests the reinforcement layer was installed using the appropriate content of asphalt emulsion after cooling of the bottom asphalt concrete beam under ambient temperature. The same compaction pressure was employed to prepare both the upper (overlay) and lower (damaged cap) asphalt concrete beams. Similar procedures to produce asphalt concrete beams were employed by Monstestuque [24] and Bühler [25].

A pre-established $16 \mathrm{~mm}$ deep $(\cong 1 / 3$ of the beam thickness) crack was produced at the bottom of the lower asphalt concrete beam aiming at simulating a bottom cracked cap. The crack was $4 \mathrm{~mm}$ wide and covered the entire beam width.

\section{Geosynthetics}

Three types of geosynthetics and a wire mesh were used in the tests. The relevant properties of the geosynthetics used are presented in Table 3. Geosynthetic Gl is a geocomposite material for pavements consisting of geogrid on a fabric coated with asphalt on both sides, as can be seen in Fig. 2a. The wire mesh (code G2, Fig. 2b) is manufactured with galvanized steel wires, $3 \mathrm{~mm}$ in diameter, forming a grid with $20 \times 20 \mathrm{~mm}$ apertures. It should be noted that 


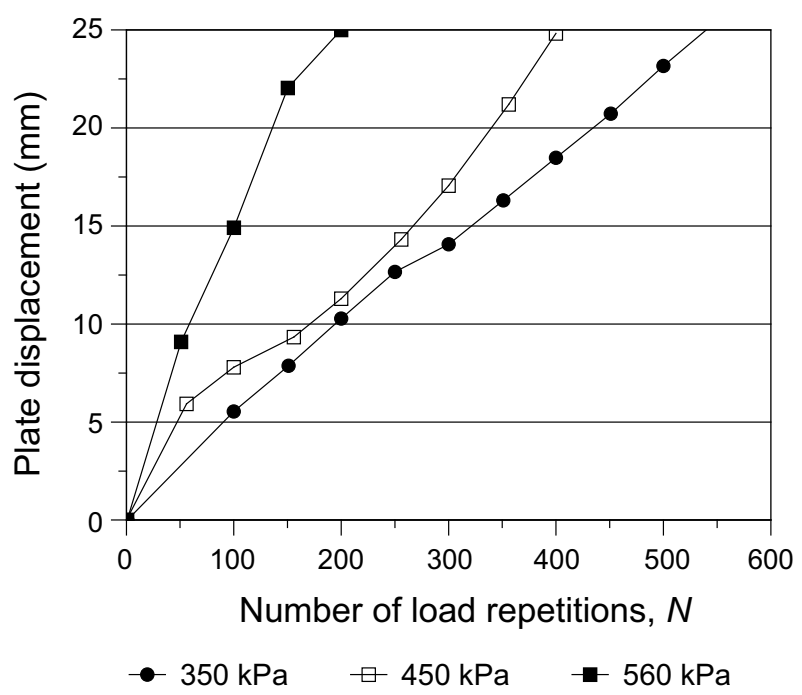

(a)

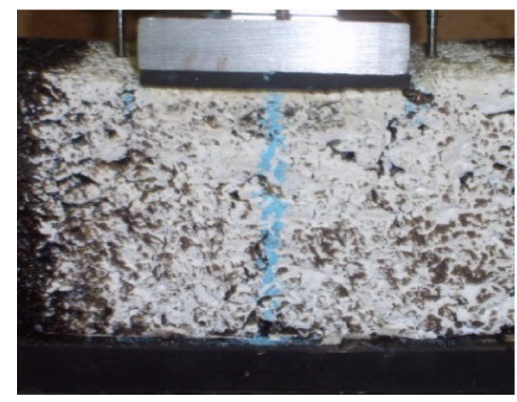

(b)

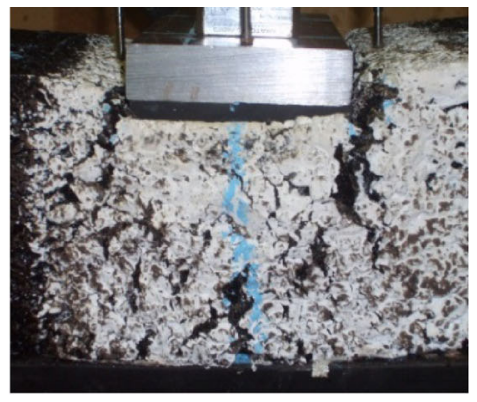

(c)

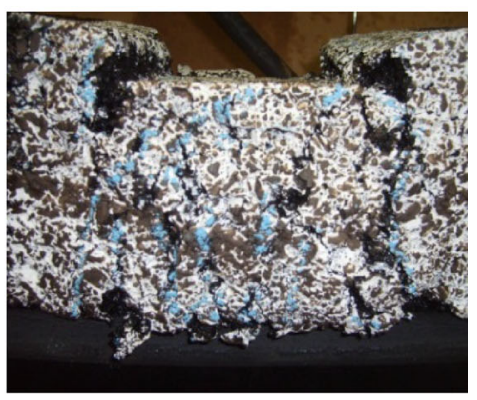

(d)

Fig. 3 Result of unreinforced beam. a Plate displacement versus number of load repetitions. $\mathbf{b} N=250$. c $N=350$. d End of test

due to its manufacturing process $G 2$ behaves as a very extensible material in in-air tensile tests, requiring rather large overall tensile strains for usual metallic grids to mobilise significant tensile forces. This extensibility is a consequence of the way the wires are connected to each other. Inside the asphalt concrete beam such deformation is restricted to some extent by the confinement provided by the surrounding material. Reinforcement $G 3$ (Fig. 2c) is an uniaxial geogrid, with $20 \mathrm{~mm} \times 20 \mathrm{~mm}$ apertures, formed by polyester filaments encapsulated in a $P V C$ cover with secant tensile stiffness values at $5 \%$ strain $\left(J_{5 \%}\right)$ of 1,390 and $557 \mathrm{kN} / \mathrm{m}$ in machine and cross-machine directions, respectively. Figure $2 \mathrm{~d}$ shows reinforcement $G 4$, consisting of a similar geogrid as reinforcement $G 3$ with $20 \mathrm{~mm} \times 20 \mathrm{~mm}$ apertures and tensile stiffness values of 875 and $585 \mathrm{kN} / \mathrm{m}$ in machine and cross-machine directions, respectively. In the asphalt concrete beams the reinforcement layers were installed with their strongest direction aligned with the direction of mobilization of maximum tension. The research programme involved tests on reinforced and unreinforced asphalt concrete beams.

\section{Results}

\section{Unreinforced Tests}

Figure $3 \mathrm{a}$ presents results of tests on unreinforced overlays under different vertical stresses in terms of loading plate vertical displacement versus number $(N)$ of load repetitions. The greater the vertical stress the sooner the loading plate reaches the final vertical displacement of $25 \mathrm{~mm}$. In the test under $560 \mathrm{kPa}$ vertical stress the maximum vertical displacement was reached after a number $(N)$ of load repetitions equal to 206, whereas for $350 \mathrm{kPa}$ normal stress the maximum vertical displacement was reached after 544 load repetitions.

Figure 3b-d shows images of the development of cracks in the unreinforced test for different values of $N$ (plate vertical stress of $450 \mathrm{kPa}$ ). At $N$ equal to 250 the first cracks appeared at the corners of the loading plate (Fig. 3b). Failure of the lower cap yielded in a punching failure mechanisms of the top cap, as shown in Fig. $3 \mathrm{c}$ $(N=350)$ and Fig. 3d (end of the test). 


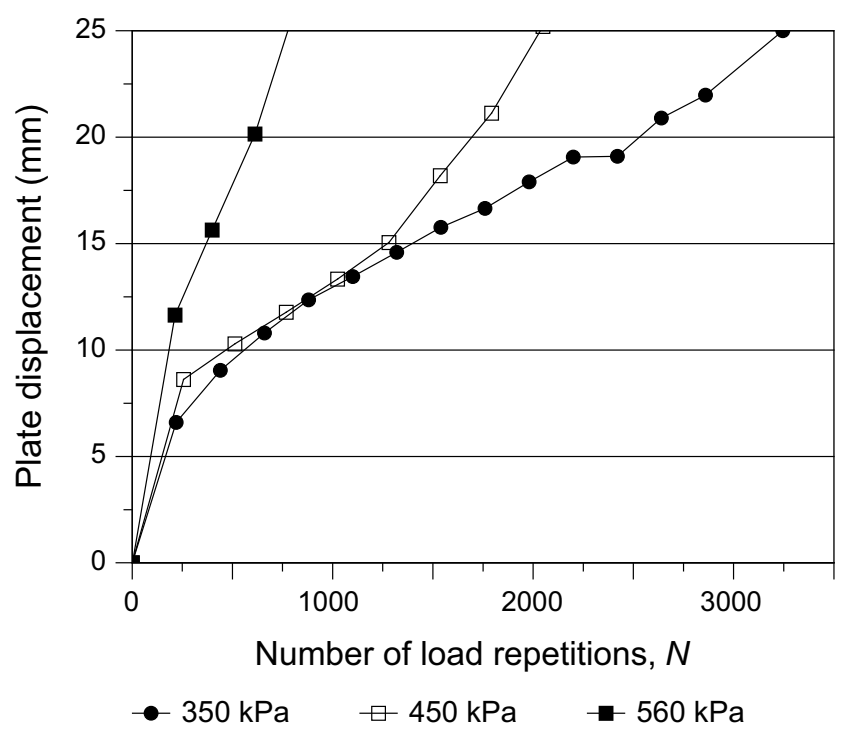

(a)

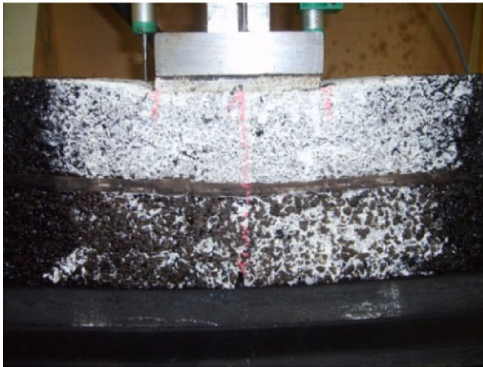

(b)

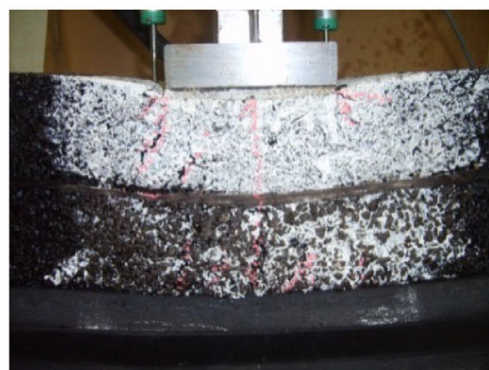

(c)

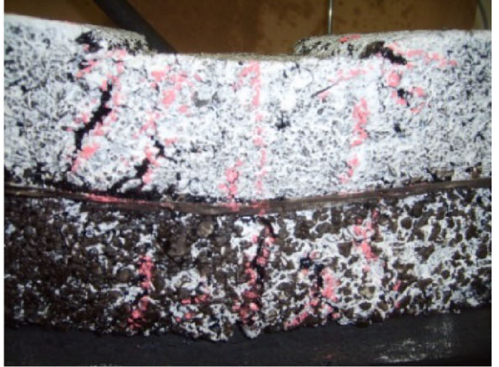

(d)

Fig. 4 Results for the beam reinforced with geogrid $G 1$. a Plate displacement versus number of load repetitions. $\mathbf{b} N=250$. c $N=1,300$. d End of test

\section{Reinforced tests}

Figures 4, 5, 6 and 7 show the variation of loading plate vertical displacement versus number of load repetitions for tests on geogrid reinforced overlays. The overlay reinforced with geocomposite $G 1$ supported in average 5 times more load repetitions than the unreinforced overlay for the different levels of vertical stress considered, with values o $N$ varying between 801 and 3,245, depending on the plate vertical stress, as shown in Fig. $4 \mathrm{a}$. It is interesting to note in this figure a distinct pattern of variation of vertical displacement with $N$ after approximately 250 load repetitions. This was the value of $N$ for which the first additional cracks were noticed in lower beam. Figure $4 \mathrm{~b}-\mathrm{d}$ present images of the asphalt concrete beams at different values of $N$ (plate vertical stress of $450 \mathrm{kPa}$ ). Comparing the results in this figure with those in Fig. 3b$\mathrm{d}$ (unreinforced overlay) one can notice that the presence of reinforcement $G 1$ attenuated considerably the severity of the crack mechanism.
The use of geogrid $G 2$ (wire mesh) increased in average approximately 7.7 times the number of load repetitions to reach maximum plate vertical displacement in comparison with the results obtained in the unreinforced case, as shown in Fig. 5a. The crack development pattern was similar to that of the test with geogrid $G 1$, as shown in Fig. $5 \mathrm{~b}$ and c, with the first cracks appearing at $N$ equal to approximately 250. However, poor adherence between the wire mesh members and asphalt concrete was noticed in this test, which may have been the main reason for a more severe crack reflection mechanism in the test with geogrid $G 2$ in comparison with what was observed in tests with the other grids. However, the development of cracks in the beams reinforced with $G 2$ was considerably delayed in comparison with was observed in the unreinforced tests. The poor adherence between $G 2$ and asphalt concrete was confirmed during exhumation of this grid from the beam for inspection after the test, as will be commented later in this paper.

The results of the test with geogrid $G 3$ are presented in Fig. 6. The presence of this grid increased the number of 
Fig. 5 Results for the beam reinforced with geogrid $G 2$. a Plate displacement versus number of load repetitions. b $N=250$. c End of test

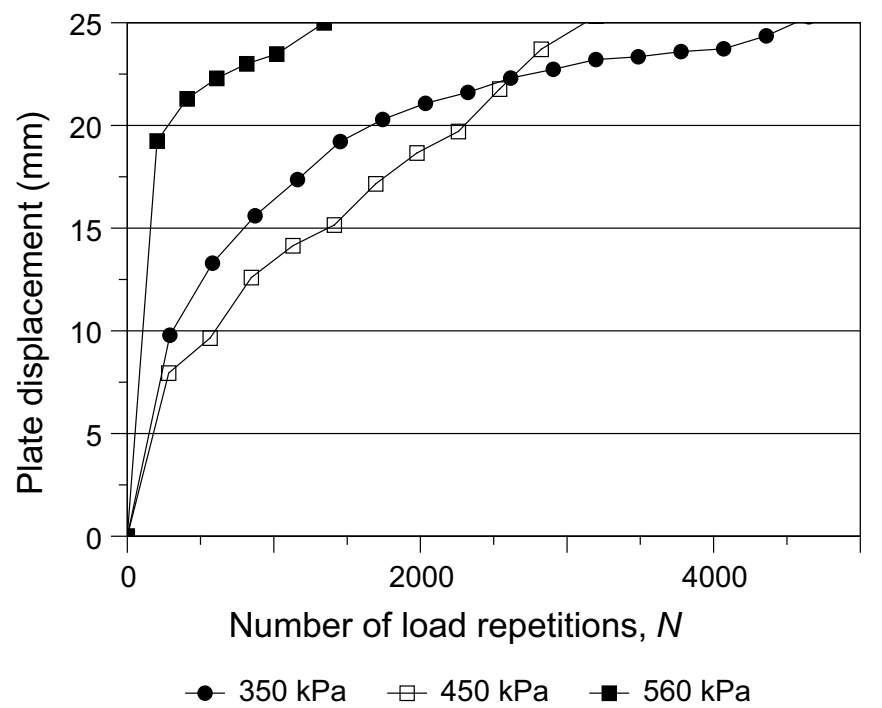

(a)

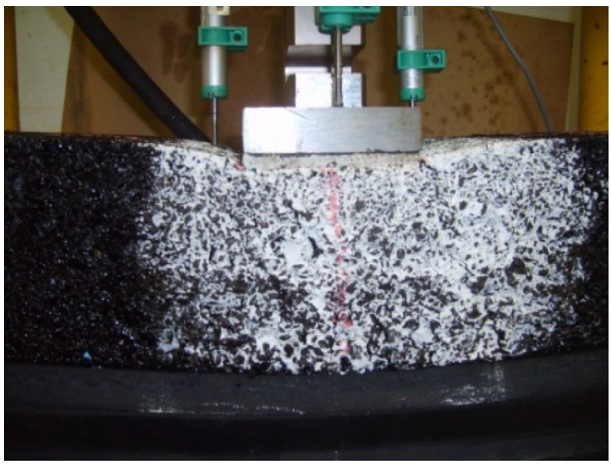

(b)

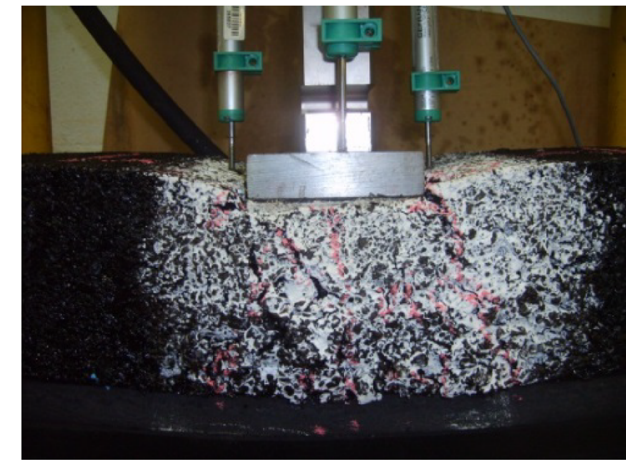

(c) load repetitions by a factor of approximately 10 with respect to the value observed in the unreinforced test (Fig. 6a). The patterns of crack development in the beam reinforced with $G 3$ are shown in Fig. $6 \mathrm{~b}$ and c and were similar to those of the previous reinforced tests described above. Despite increasing significantly the number of load repetition for maximum vertical displacement, rather poor adherence between $G 3$ and the asphalt concrete was also noted in this test, which also accelerated the reflection of the cracks from the underneath cap to the overlay (Fig. 6b, c).

The best performance in terms of increase in the number of load repetitions for maximum vertical displacement was obtained in the test with geogrid $G 4$, as shown in Fig. 7. In this case the number of load repetitions was in average 16.6 times greater than that obtained in the unreinforced test for the different plate vertical stresses used. A change of pattern of variation of vertical displacement with $N$ was noted for $N$ approximately equal to 600 (Fig. 7a), when the first cracks were noticed (Fig. 7b), in contrast with the value of approximately 250 observed for the previous reinforced tests. Damages to the overlay were also noticed in the test with geogrid $G 4$, but in the form of small fissures. Therefore, as in the previous reinforced tests the presence of the reinforcement did not avoided crack reflection but delayed considerably its development.

Figure 8 summarises results of tests on unreinforced and reinforced overlays in terms of number of load repetitions required to reach the maximum vertical displacement of $25 \mathrm{~mm}$ versus vertical pressure on the loading plate. This figure shows a rather linear variation of vertical pressure with $N$ in a semi-log plot, where $N$ decreases with the increase of plate vertical stress. The results also show that despite having the same aperture, the performance of geogrids $G 2, G 3$ and $G 4$ was quite different, having been certainly influenced by different levels of adherence between geogrid and asphalt concrete.

Values of efficiency ratio $(E R)$ for the reinforcements tested are shown in Fig. 9 as a function of the vertical stress applied on the asphalt concrete beam. The ER is defined as the number of load repetitions for a plate displacement of $25 \mathrm{~mm}$ in a reinforced test divided by the 
Fig. 6 Results for the beam reinforced with geogrid $G 3$. a Plate displacement versus number of load repetitions. b $N=250$. c End of test

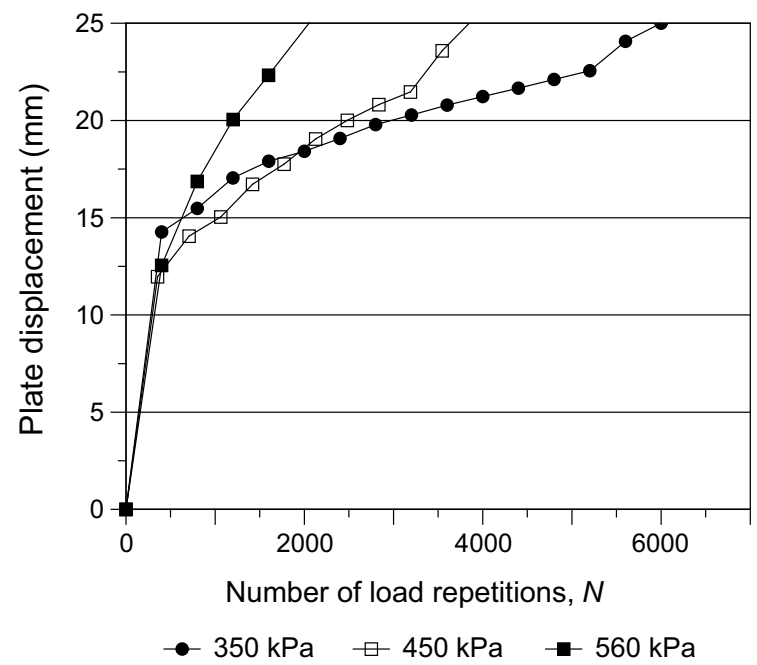

(a)

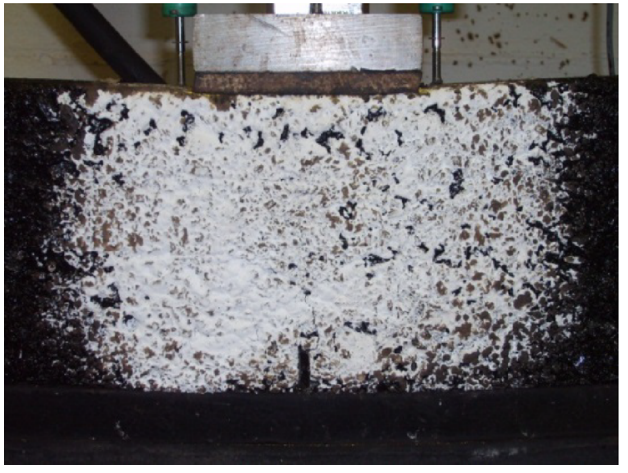

(b)

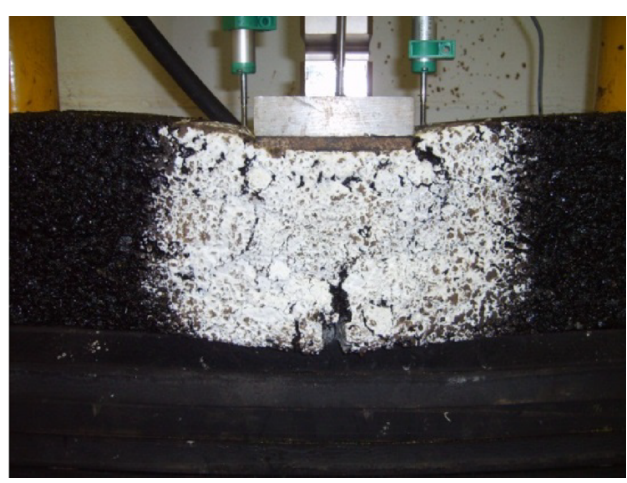

(c) number of load repetitions in the unreinforced test for the same displacement. The value of $E R$ varied between 4 and 18.8 , depending on the reinforcement and vertical stress considered, with greater values (between 15.3 and 18.8) having been observed in the tests with geogrid $G 4$. The less effective reinforcement regarding the increase in the number of load cycles was Gl (geocomposite). This less effective performance can be attributed to the smaller tensile stiffness of $G 1$ and greater aperture size (twice as much as those of the other grids) in comparison with the other reinforcements tested.

Images of exhumed reinforcement specimens after the end of the tests are depicted in Fig. 10. No visible damages caused by sample preparation conditions (compaction and temperature) were noted in the geogrids after the tests. The easiness or difficulty in exhuming the specimens was an indirect assessment of the adherence between geogrid and asphalt concrete. A significant degradation of the asphalt coated fabric in reinforcement $G l$ was noted after the test, but pieces of that fabric remained for the test conditions employed in this study (Fig. 10a). From the exhumation process it could be noticed that the geocomposite $G l$ was the reinforcement with greatest adherence to the asphalt caps. On the other hand, the wire mesh $G 2$ was the reinforcement with least adherence to the caps. The latter factor explains the less performance of reinforcement $G 2$ in comparison with geogrids $G 3$ and $G 4$, despite its higher tensile stiffness.

\section{Conclusions}

This paper presented and discussed results of tests on reinforced and unreinforced concrete asphalt caps focusing on the use of geosynthetic reinforcement in asphalt overlays. The main conclusions from this study are summarized below.

Crack reflection was observed in all tests performed, but it was considerably more severe in the unreinforced case. Reinforced caps resisted between 4 and 18.8 more load cycles than the reference unreinforced cap, depending on the type of reinforcement and vertical stress considered. 
Fig. 7 Results for the beam reinforced with geogrid $G 4$. a Plate displacement versus number of load repetitions. b $N=600$. c End of test

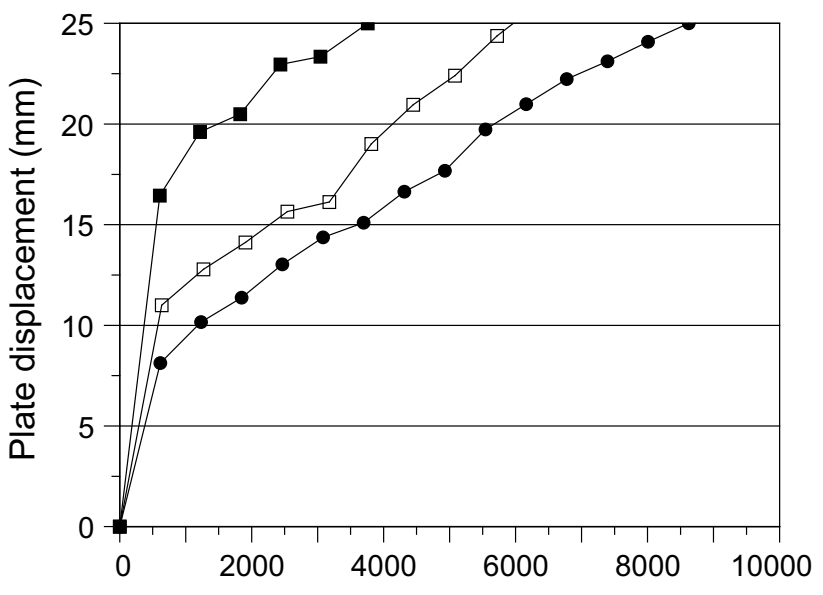

Number of load repetitions, $N$

(a)

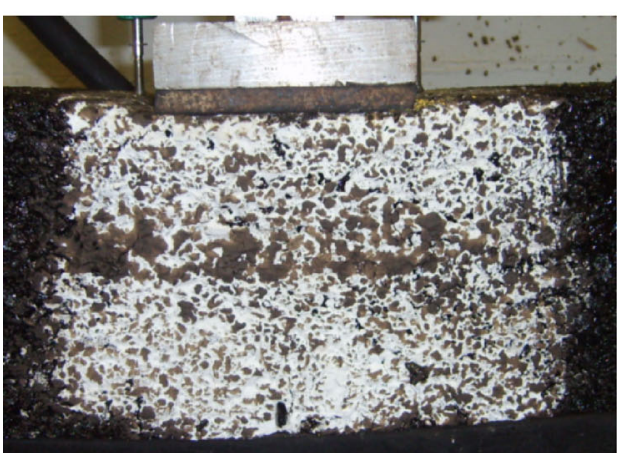

(b)

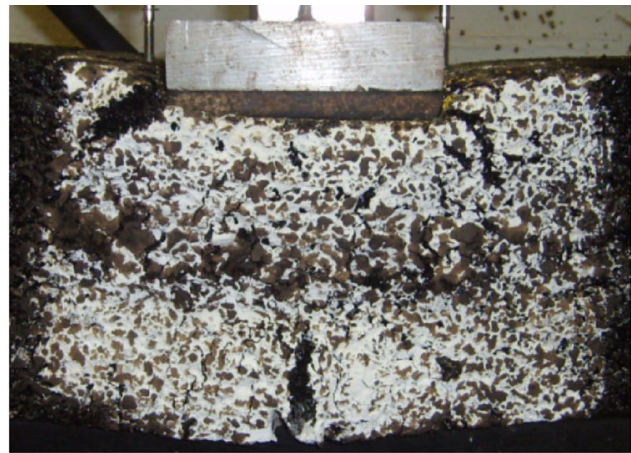

(c)

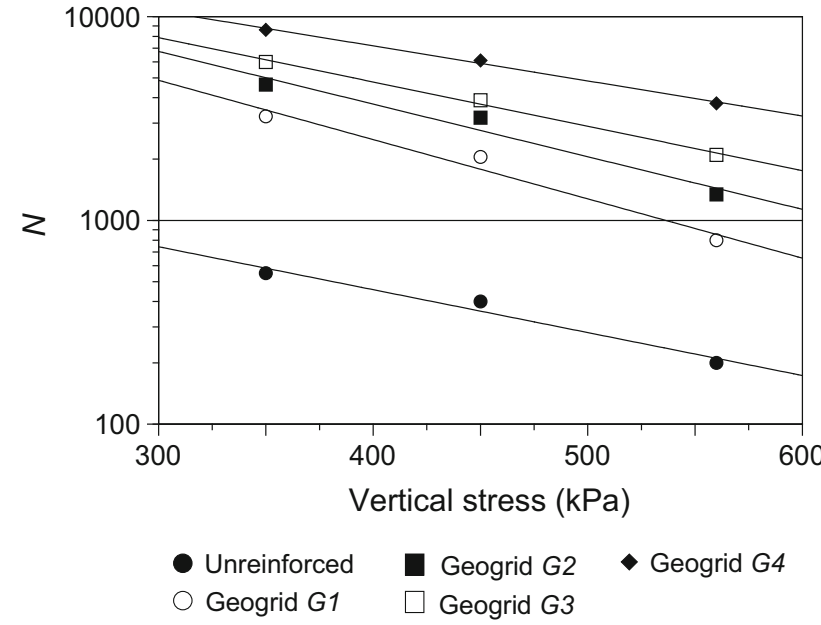

Fig. 8 Final number of load repetition versus maximum plate vertical stress for unreinforced and reinforced tests

The larger the vertical stress on the beam the less the number of load cycles resisted by the beam in unreinforced and reinforced cases.

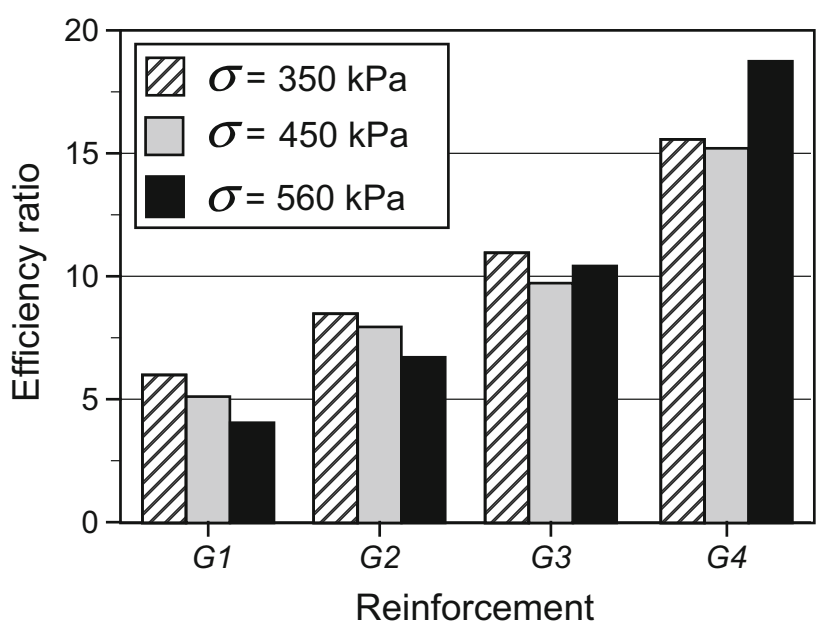

Fig. 9 Efficiency ratio values for different geogrids

Images obtained during the tests showed that the crack propagation and damage to the beam were much more severe in the unreinforced case in comparison with the reinforced ones. 
Fig. 10 Exhumed reinforcement specimens after the tests. a $G 1$, b $G 2$, c $G 3$, d $G 4$
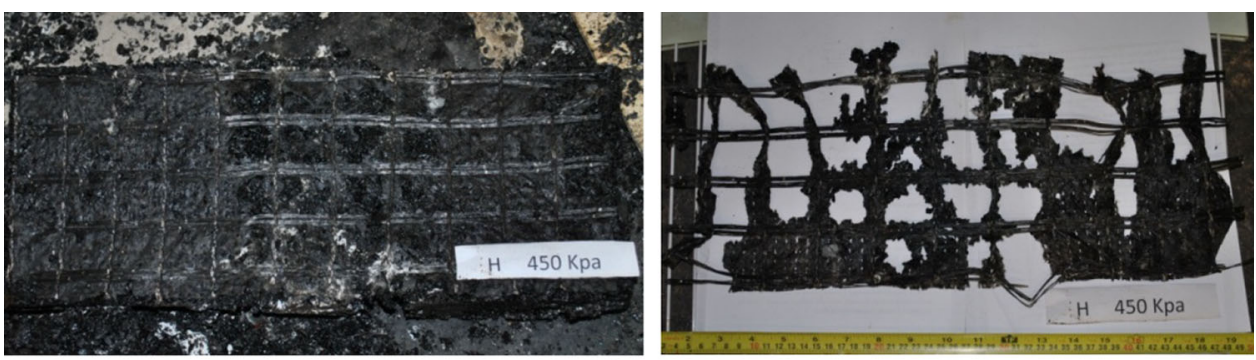

(a)
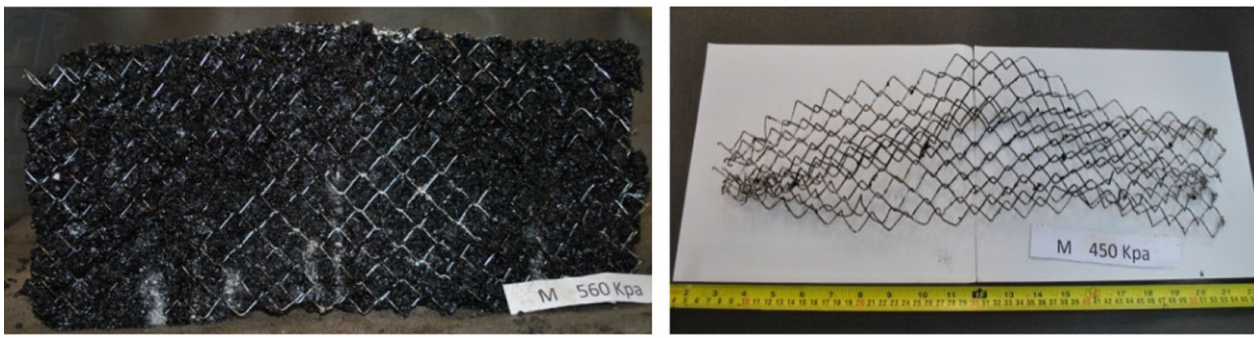

(b)
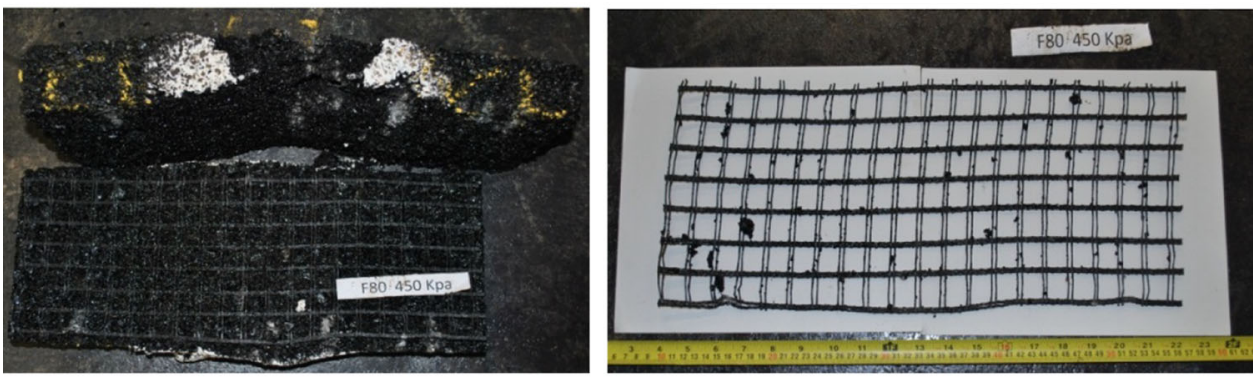

(c)
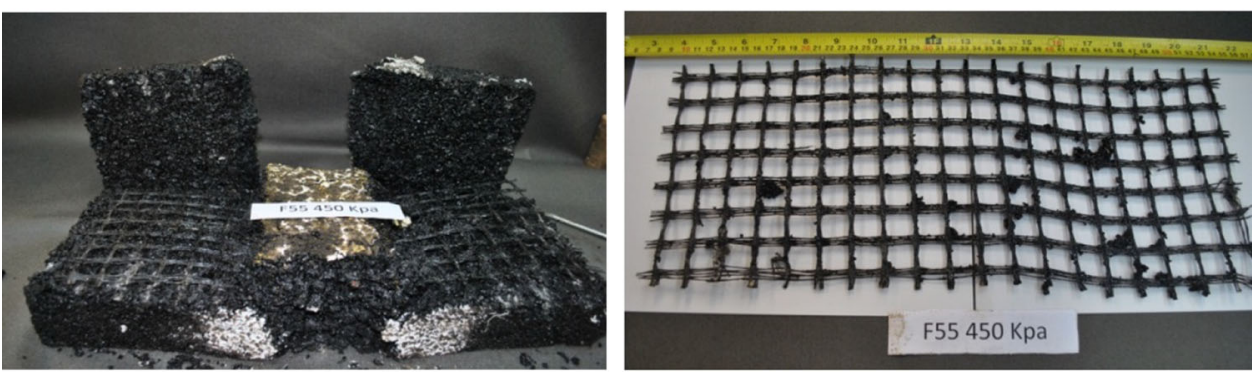

(d)

The geocomposite consisting of a geogrid on an asphalt coated fabric was the less effective reinforcement in terms of increases in number of load repetitions. Nevertheless, the beam reinforced with the geocomposite resisted between 4 and 5.9 times more load repetitions than the unreinforced beam. The less performance of this reinforcement may be related to its smaller tensile stiffness and larger aperture size in comparison with those of other the reinforcements tested. The asphalt coated can degrade partially or entirely during construction, leaving just the geogrid to fulfill the reinforcement function. The exhumed specimens showed that the asphalt coated fabric degraded significantly but not entirely for the conditions of the tests performed in the present study.

The behaviour of reinforced overlays is very complex and much research is required for the development of reliable design methods. Further research is in progress for a better understanding on the performance of geosynthetic reinforced overlays.

Acknowledgments The authors are indebted to the following institutions that cooperated with the research programme reported in 
this paper in different ways: University of Brasília and CNPQNational Council for Scientific and Technological Development.

\section{References}

1. Haas R, Wall J, Carol RG (1988) Geogrid reinforcement of granular bases in flexible pavements. Transp Res Rec 1188:19-27

2. Webster SL (1992) Geogrid reinforced base courses for flexible pavements for light aircrafts: literature review and test section design. Technical Report GL-92-926, USAE, Waterways Experiment Station, Vicksburg, Mississippi, USA, p 33

3. Webster SL (1993) Geogrid reinforced base courses for flexible pavements for light aircraft, test section construction, behavior under traffic, laboratory tests and design criteria. Technical Report GL-93-936, USAE, Waterways Experiment Station, Vicksburg, Mississippi, USA, p 86

4. Al-Qadi IL, Brandon TL, Valentine RJ, Lacina BA, Smith TE (1994) Laboratory evaluation of geosynthetic reinforced pavement sections. Transp Res Rec 1439:25-31

5. Austin RA, Gilchrist AJT (1996) Enhanced performance of asphalt pavements using geocomposites. Geotext Geomembr 14:175-186

6. Perkins SW, Ismeik M (1997) A synthesis and evaluation of geosynthetic-reinforced base layers in flexible pavements: part I. Geosynth Int 4(6):549-604

7. Perkins SW, Ismeik M (1997) A synthesis and evaluation of geosynthetic-reinforced base layers in flexible pavements: part II. Geosynth Int 4(6):605-621

8. Perkins SW (1999a) Geosynthetic reinforcement of flexible pavements: laboratory based pavement test sections. Final Report FHWA/MT-99-001/8138, State of Montana Department of Transportation, MT, USA, p 140

9. Perkins SW (1999) Mechanical response of geosynthetic-reinforced flexible pavements. Geosynth Int 6(5):347-382

10. Cancelli A, Montanelli F, Rimoldi P, Zhao A (1996) Full scale laboratory testing on geosynthetics reinforced paved roads. In: Proceedings of the international symposium on earth reinforcement, IS-Kyushu 1996, Kyushu, Japan, vol 1, pp 573-578

11. USACE (2003) Use of geogrids in pavement construction. Technical Letter 1110-1-189, United States Army Corp of Engineers, Washington, DC, p 38

12. Al-Qadi IL, Dessouky SH, Kwon J, Tutumluer E (2007) Accelerated full-scale testing of geogrid-reinforced flexible pavements. Transportation Research Board, 86th annual meeting, Washington, DC, USA, CD-ROM, p 27

13. Perkins, SW, Christopher BR, Thom N, Montestruque G, Korkiala-Tanttu L, Watn A (2010) Geosynthetics in pavement reinforcement applications. Proceedings of the 9th international conference on geosynthetics, Guarujá, Brazil, vol 1, pp 165-192
14. Hosseini HRA, Darban A, Fakhri K (2009) The effect of geosynthetic reinforcement on the damage propagation rate of asphalt pavements. Scientia Iranica 16:26-32

15. Khodaii A, Shahab F, Fereidoon MN (2009) Effects of geosynthetic on reduction of reflection cracking in asphalt overlays. Geotext Geomembr 27:1-8

16. Virgili A, Canestrari F, Grilli A, Santagata FA (2009) Repeated load test on bituminous systems reinforced by geosynthetics. Geotext Geomembr 27:187-195

17. Ferroti G, Canestrari F, Virgili A, Grilli A (2011) A strategic laboratory approach for the performance investigation of geogrids in flexible pavements. J Constr Build Mater 25:2343-2348

18. Barraza DZ, Contreras JN, Fresno DC, Zamanillo AV (2011) Evaluation of anti-reflective cracking systems using geosynthetics in the interlayer zone. Geotext Geomembr 29:130-136

19. Ribeiro LR, Carvalho JC, Palmeira EM (2005) The use of alternative and improved construction materials and geosynthetics in pavements. In: Indraratna B (ed) Ground improvement case histories. Elsevier, London, pp 765-786

20. Fritzen MA (2005) Evaluation of asphalt pavement reinforcement solutions with a traffic simulator in the Rio-Teresopolis highway. M.Sc. Dissertation, Coppe-Federal University of Rio de Janeiro, Brazil (in Portuguese)

21. ASTM D7460 (2010) Standard test method for determining fatigue failure of compacted asphalt concrete subjected to repeated flexural bending. American Society for Testing Materials, West Conshohocken

22. Komatsu T, Kikuta H, Tuji Y, Muramatsu E (1998) Durability assessment of geogrid-reinforced asphalt concrete. Geotext Geomembr 16(5):257-271

23. Zhou WL, Wang Z, Zhang HM (2007) Field trial for asphalt pavements reinforced with geosynthetics and behavior of glassfiber grids. J Perform Constr Facil ASCE 361:1-12

24. Montestruque GE (2002) Contribution to the development of a design method for repair of asphalt pavements using geosynthetics in systems against crack reflection. Ph.D. Thesis, Instituto Tecnologico da Aeronautica-ITA, Sao Jose dos Campos, SP, Brazil (in Portuguese)

25. Bühler A (2007) Study on the effect of grid reinforcement in pavement repair. Ph.D. Thesis, Instituto Tecnologico da Aeronautica-ITA, Sao Jose dos Campos, Brazil (in Portuguese)

26. Pasquini E, Bocci M, Canestrari F (2014) Laboratory characterisation of optimised geocomposites for asphalt pavement reinforcement. Geosynth Int 21(1):24-36

27. ASTM D6637 (2001) Standard test method for determining tensile properties of geogrids by the single or multi-rib tensile method. American Society for Testing Materials, West Conshohocken 